\title{
Managing a Large-Scale Weeding Project
} When We All Pull Together

By Leslie A. Engelson, Murray State University

ABSTRACT The main circulating collection at Murray State University had never been thoughtfully and intentionally weeded. Several factors aligned, raising the need for a thorough weed of the collection resulting in weeding over a quarter of the collection (over 100,000 volumes). Most of the volumes were pulled and processed over a 32-week period. This session will discuss the circumstances that made the time ripe for weeding, the criteria that informed the decision-making process, tools used in that process, workflow for accomplishing the physical processing, cross-library participation in the project, and things to consider when implementing a project of this magnitude.

\section{SITUATION}

The circulating collection at Murray State University (MSU) consisted of approximately 300,000 volumes and includes the oversize collection. It was created primarily by faculty selecting resources, as well as the consolidation of department libraries into the University Libraries system. The various areas of the collection have never been systematically developed or weeded, and the Research \& Instruction (R\&I) librarians have maintained a hands-off approach. As you can imagine, this created a spotty and inconsistent collection.

An analysis of the collection in 2013 revealed that the average date of publication of the resources in the collection was 1973, with most books published in 1968. Ninety percent of the titles were published before 2003. The oldest area of the collection was the CNs (Inscriptions, Epigraphy), with an average publication date of 1945, and the most current area of the collection was ZA (Information sciences), with an average publication date of 2007. Almost half of the collection 


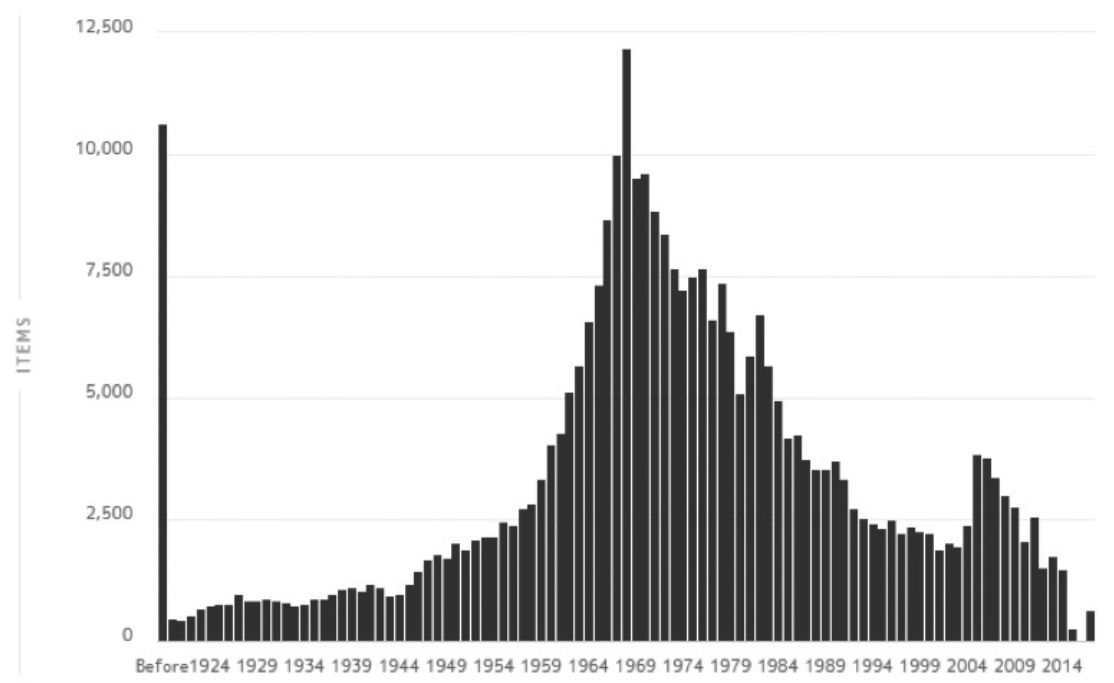

has not circulated since 2000 . Of those that have circulated, only $13 \%$ have circulated five or more times.

Students often complained (on social media as well as formal surveys) of the lack of space. No private or group study rooms were available, and they often had to sit on the floor because all the seating was in use. Circulation statistics had been decreasing from about $15 \%$ in $2011 / 2012$ to about $12 \%$ in $2016 / 2017$, while the availability and use of electronic resources was increasing.

The R\&I librarians were insecure about making weeding decisions because of their lack of experience and traditionally hands-off approach. Because of my experience with collection management, as well as a recent presentation on collection analysis tools at an ATLA conference, I approached the dean about making a similar presentation to the R\&I librarians. As part of the discussion, we determined some goals for the project.

\section{PROJECT GOALS}

Establishing a desired collection strength and preferred format for subject areas was one of the first goals. The R\&I librarians worked diligently to determine, based on curricular needs, the desired strengths of the areas of the collection they were responsible for. This gave them a better understanding of the target they were trying to reach as they made retention decisions. 
Secondly, they reviewed the circulating collection for items which were no longer relevant due to a change in programs and curricular needs.

An important goal of the project was to disseminate the withdrawn materials in a responsible manner. Because MSU is a state institution, there are legislative requirements that restrict how materials can be disposed of, but we were concerned about ensuring that as many titles as possible could be given away or sold and not put in the landfill.

The fourth goal was to start reaching the desired collection strength through acquisitions and access-based models.

Finally, the last goal was to renovate the space to create study areas for individuals and groups.

Since the establishment of these goals, we have had a change in leadership. The first, second, and third goals have been met, but it is unlikely that formally initiating efforts to meet the fourth goal of determining current collection strengths with the intention of developing the areas will happen. The fifth goal has been partially met but was limited based on a lack of funding.

\section{CONTRACTS}

A result of the collection management presentation was a decision to contract with Sustainable Collection Services (SCS) for the use of their GreenGlass collection analysis tool and with Better World Books (BWB) to disseminate materials in a more sustainable way.

Contracts with both SCS and BWB were discussed with the University Procurement Services office at length, as they had to conform to state law. There were quite a few hurdles with this process, because this department doesn't understand how libraries do business, and their interpretation of state law regarding contracts and how materials purchased by the University can be disposed of is very rigid. In the end, they approved the contract with GreenGlass without going out to bid, as well as giving withdrawn books to Better World Books to sell for us.

\section{PROCESS}

After sending SCS a file of 309,156 bibliographic records with 338,560 associated item records, SCS built a database of those records along 
with data from other databases such as WorldCat, HathiTrust, and Choice Reviews. This allowed us to compare our holdings with those of other universities in Kentucky, as well as benchmark libraries we had identified. Additionally, we could determine if the titles were available in full text in open access databases such as HathiTrust, as well as look at reviews in Choice Reviews. The interface provided the ability to search by and report on date of acquisition, publication data, circulation count, last circulation day, and LC call number range. The data in GreenGlass was current as of the date it was extracted from our ILS. Because it is not connected to our ILS, it is only a snapshot in time. We still have access to our GreenGlass database, but it does not reflect recent acquisitions, current circulation data, or the fact that we no longer own many of the items that are represented in the database.

\section{CRITERIA}

While we were waiting for the database to be created, the R\&I librarians established what we called "no-brainer" criteria that I could use to start the weeding process. These criteria fit the parameters of the type of collection we were developing (a current circulating collection that is appropriate for the community served and curriculum supported). Once these were established, I was able to run reports in our ILS and start withdrawing the following materials:

- Superseded editions

- Foreign languages not currently taught

- Textbooks published before 1995

- Medical or clinical books older than 1985

- Software books published prior to 2007

- Workbooks, lab books, study guides intended to be written in

- Unmendable materials or those that are more expensive to mend than to replace

- Duplicate copies published prior to 2010

- Books that clearly do not support the curriculum

Criteria were also established that excluded materials from being weeded. These criteria included: 
- MSU authors

- MSU theses

- Books added in the last 5 years

- Books circulated a significant number of times

- Books related to the region

- Last Kentucky library to hold

Additionally, the R\&I librarians established criteria for the areas of the collection for which they were responsible. These criteria were used to run reports in GreenGlass from which titles were selected for withdrawal. From these reports, 113,858 titles were identified for withdrawal, which equated to $37 \%$ of the collection.

\section{WORKFLOW}

Query results in the SPS database were exported in Excel spreadsheets and included the query parameters. The R\&I librarians would then remove items from the spreadsheet that matched the excluded criteria, and then the spreadsheets were loaded into a folder on a shared drive.

Keeping the original spreadsheets intact in order to keep a record of the query used and its results, I compiled each list into a master list, removing information that was not relevant for my needs. The information that remained included:

- Location code (CIR or FOL)

- Call number

- Enumeration or Chronological data (from item record)

- Title

- Barcode

This project was initiated in 2013. Throughout 2014-2015, the R\&I librarians made deselection decisions. The project was then put on hold for a couple of years, as we had a change in deans. Additionally, the previous dean had promised the faculty that they could review the books before we withdrew them. However, the new dean struggled with the logistics of how that could happen, given the interdisciplinary nature of college curriculum, and was able to get approval from the 
provost to withdraw the books without faculty review. The withdrawing part of the project began on August 28, 2017, and was stopped on November 15, 2018.

A total of nine staff and sixteen students from across library departments participated in the actual physical withdrawing process. Some helped throughout the entire project, and some just helped once. Each person's participation was voluntary, and they were able to come and go during the project as other responsibilities affected their availability.

Once I was given approval to begin withdrawing materials, I decided to start in the Zs and work our way forward. One reason for this was that the Q-Zs were in an area of the library that had high humidity, which caused outbreaks of mold. We had the mold remediated twice, but the problem would continue to happen unless the books were removed from this area. Additionally, this area was on the side of the building that was selected for the major part of the renovation. Thus, it seemed like this was the best area to tackle first.

To begin, I printed out the spreadsheet, bundling eight or nine pages together for about two hundred titles per bundle. In order to keep track of which titles had been printed and which had been withdrawn, I highlighted the titles printed in blue in the spreadsheet. Once they were withdrawn, I changed the highlighting to grey. I kept a running list of each bundle by LC letter and page numbers in a separate spreadsheet along with the name of each person responsible for that bundle and the number of books in each bundle.

This helped me monitor when lists were completed, who was responsible for that call number area, and who to go to if I had any questions. It also helped me keep track of how many had been withdrawn so I could report this at a bi-monthly department heads meeting.

Each person was responsible for pulling and processing the titles on their list. They had their own cart, as well as a piece of paper with their name printed on it in a large font. If they had to stop in the middle of completing their bundle, they would leave the books on their cart with their name sheet on top and then would pick up where they left off when they were able to come back to the task. This minimized steps in the process getting accidently skipped because it was unclear what stage the books were at in the process. 
The pulling process involved locating the book by call number and comparing the title and barcode to that listed on the sheet. If the title was found, it was marked with a checkmark $(V)$ next to the barcode. If the title was not found, it was marked with a "not" symbol $(\varnothing)$. Sometimes the call number would match but the barcode would not, or the barcode would match and the call number would not. This was usually due to a mistake in the record, and the book was the one listed for withdrawal.

After the books were pulled, they were then searched for by ISBN in BWB's database to determine if the title was one that they wanted. If so, it was added to a box for BWB. If not, it was placed in a bin for recycling or discard. All books were physically processed for withdrawal by crossing through the barcode and spine label with a black permanent marker and stamping DISCARD on the top of the text block and title page. We do not want these books making their way back to the library, so, want to make it clear that they have been withdrawn.

In addition to providing the boxes, BWB provided free pick-up and shipping. We had to have at least six boxes for pickup, and they could be sent either through the mail or by freight. Freight shipping requires forty boxes on a pallet that is shrink-wrapped and a loading dock. It was determined that this was too much work for shipping/receiving to manage. When we accumulated at least six boxes, we communicated with BWB to let them know and received postage, which we printed out and applied to the boxes. We then contacted shipping/receiving to let them know how many boxes were ready for pick-up.

Coordination with the maintenance department and shipping/ receiving was essential, as we had countless bins of books for maintenance to pick up and dispose of and often ten to sixteen boxes daily for shipping/receiving to pick up. Their staffing and schedule were impacted, so it was important to communicate with those departments about the project early on.

At one point we ran out of BWB boxes, and so had to find space to store the withdrawn books until additional boxes arrived.

When all the titles in a bundle were pulled, the bundle was returned to me. I would then batch withdraw the titles on the list from our ILS using the barcodes on the spreadsheet. Titles that were not found were searched in the ILS to see if we still had the item or if it was checked out or lost. A circulation staff member who was good at finding missing 
books did a second search for those that were supposed to be on the shelf and often found many of those missed in the first search.

At the end of each month, I ran a report of titles withdrawn, which included the OCLC number. I then batch removed our holdings from WorldCat using the numbers from that report.

What is a major project without a progress chart? With this project, ours was a Progress Shelf consisting of previously discarded books. Each book represented 1,100 books to withdraw. For each 1,100 books withdrawn, the person who turned in the spreadsheet that included the 1,100th book got to pull a book from this shelf.

While we were waiting for the project to begin, the Cataloging student workers created book covers using their creativity and senses of humor to come up with clever book titles and authors. It was a fun part of the project to be able to pull a book from the Progress Shelf and see what the title would be. Some examples are Charlotte's Website by E.Z. White, Baker's Men by Pat E. Cake, and Downpour by Wayne Dwops.

I made sure that everyone who was involved

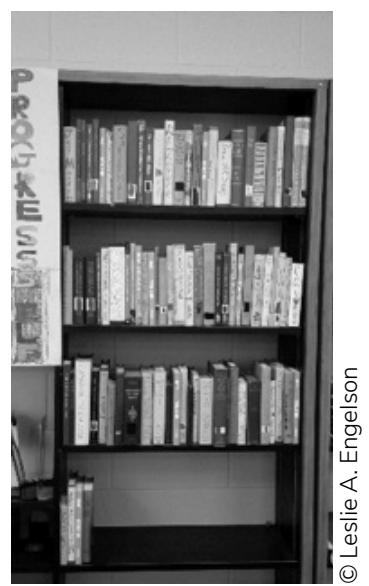
in the project long-term got to pull a book from the Progress Shelf. This was a great visual reminder of where we were at in the project and how much farther we had to go.

\section{END OF PROJECT}

The library is a popular and busy place on campus. During peak times, students often have to sit on the floor because there is no available space at the tables and chairs. When this project was initiated in $2013 / 2014$, one of the goals was to withdraw a quarter of the collection in order to be able to renovate the entire area. The plan was to install group study rooms as well as a reading area in order to address the ongoing complaints about the lack of space that were voiced in surveys as well as on social media.

However, the budget situation started to decline in 2015 and has steadily gotten worse. Possible funding for the renovation 

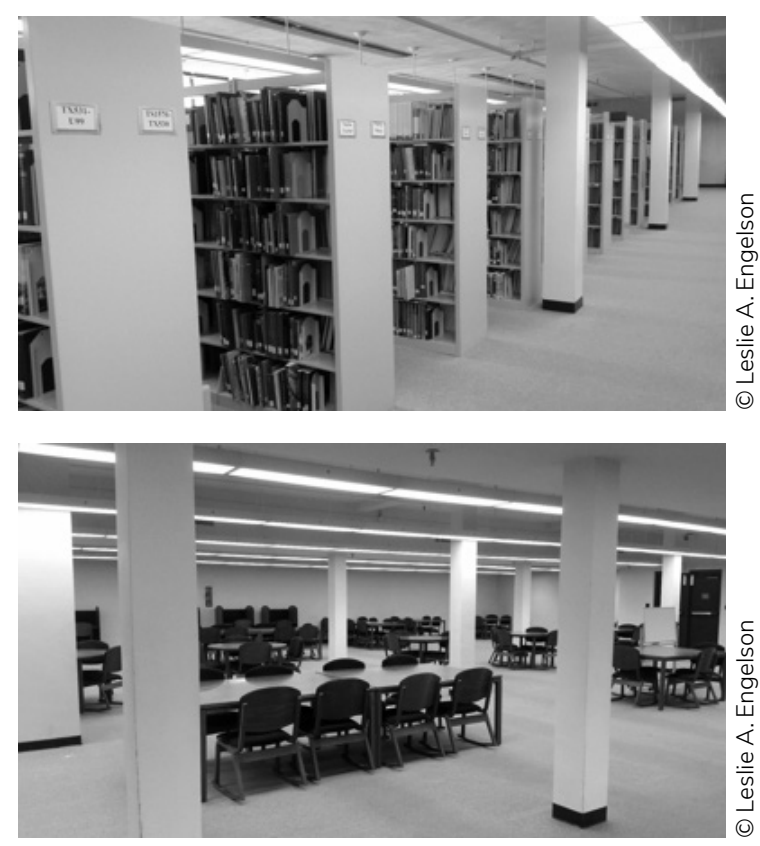

disappeared. The dean was concerned that, if we finished withdrawing all the materials in the master withdraw spreadsheet, we would have too many empty shelves. The decision was made to withdraw enough books so that we could shift the remaining books out of the area where humidity was a problem and move in tables and chairs and study carrels in order to create some study space.

The picture shows the area with the high humidity before the project. As you can see, it is filled with stacks upon stacks of books.

This is how that same area looks now. It is a popular area for students, and we have had no complaints about the removal of the books.

\section{OUTCOMES}

As of June 5, 2018, we have received almost $\$ 5,000$ from the sale of 3,552 books of those that were sent to BWB. Additionally, 2,445 of the books sent were recycled. BWB provides environmental metrics that demonstrate the positive impact on the environment of selling or recycling these books rather than sending them to the dump. The environmental metrics indicate that we have saved 96 trees, almost $13,000 \mathrm{lbs}$ of greenhouse gases, and 113 cubic yards of landfill space. 
This is just the number of books sold or recycled. I did not keep track of the total number of books sent.

When the project ended, we had withdrawn all the books on the withdraw spreadsheet that were in the P-Z range. This totaled 50,438 books and was $44 \%$ of the total project.

However, a pleasant and unexpected outcome was the unification and comradery enjoyed by students and staff crossing departmental boundaries and working together on such a massive project. I got to know students from other departments who I had never spoken to before. Relationships with staff in other departments improved, which now facilitates communication with the cataloging department. The library came together for a mutual purpose, resulting in a sense of unification and mutuality. We were all truly sad when the project ended; not just because we didn't get to complete it, but because we had such a positive experience with it. 